\title{
IT'S ON A ROLL: DRAPING COURSES OF GLASS FIBER FABRIC IN A WIND TURBINE BLADE MOLD BY MEANS OF OPTIMIZATION
}

\author{
$\underline{\text { Christian Krogh }}^{*}$, Jørgen A. Kepler $^{1}$, Johnny Jakobsen ${ }^{1}$ \\ ${ }^{1}$ Department of Materials and Production, Aalborg University, \\ Fibigerstraede 16, 9220 Aalborg, Denmark. \\ *ck@mp.aau.dk
}

Wind turbine blades are manufactured from light and strong composite materials. The fiber material, predominantly glass fiber non-crimp fabric (NCF), is rolled out in the blade mold in courses and subsequently infused with the resin. The blade designers will typically specify e.g. the fiber orientations and thicknesses in various regions of the blade. These instructions must be translated into what courses to be placed where in the mold while at the same time paying attention to draping effects, i.e. shearing arising from double mold curvatures. Draping on a double-curved mold can be analyzed with a kinematic draping algorithm [1], e.g. commercially available with programs such as Composites Modeler for Abaqus/CAE, Ansys ACP and Fibersim. Although simple and kinematic, the draping model can predict the draped pattern with reasonable accuracy with a low computational effort. To this end, the applicability of optimization techniques is attractive, see e.g. ref. [2] in which a Genetic Algorithm (GA) is employed. Figure 1 shows the first results of the present study on course optimization, obtained by draping a single course along the right edge of a blade section and letting a GA determine the optimal starting point, i.e. a point of zero shear, to minimize the aggregated shear angles. As it can be seen, the maximum shear angle can be decreased from $10.8^{\circ}$ to $2.7^{\circ}$ if the starting point is moved from the lower right corner to a position in the center of the course.
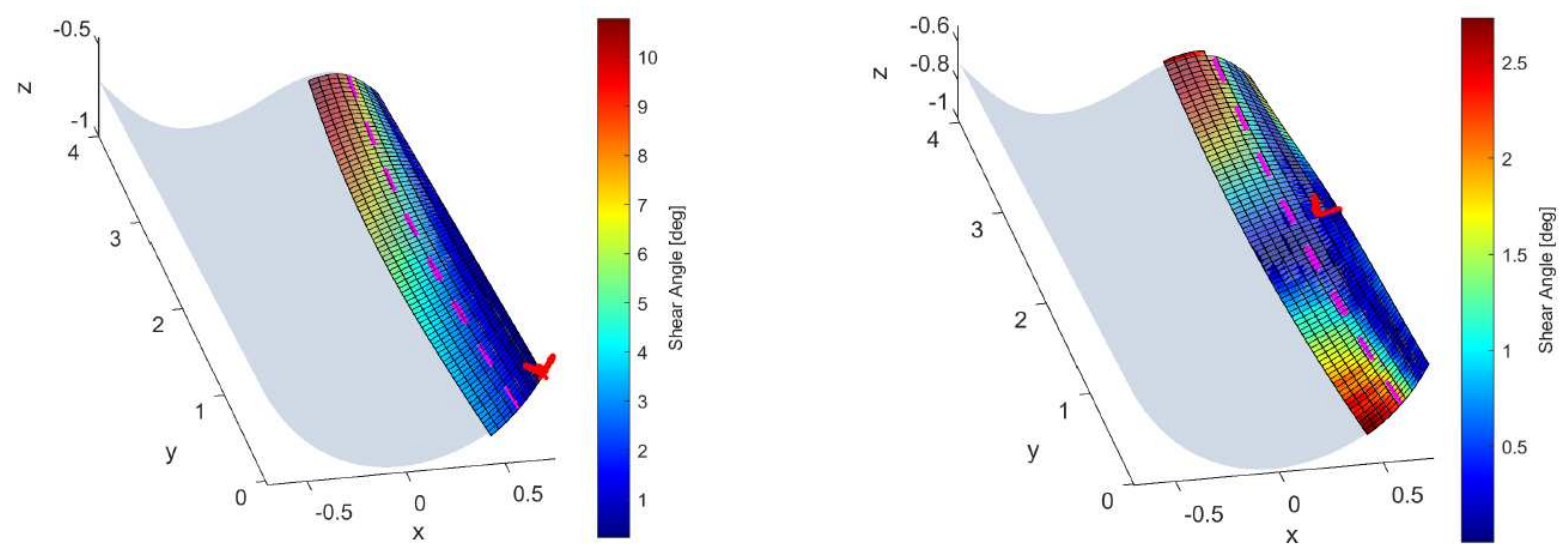

Figure 1. Draping of a single course in blade mold section. Left: starting point in lower right corner. Right: optimized starting point using GA minimizes the shear angles.

The next step is to expand the analysis to include an entire layer, i.e. multiple courses. More criteria will also be added such as the fibers being oriented as close as possible to the specification as well as minimizing the material trim-off, i.e. waste. Eventually this framework can serve as an aid for automating the draping process.

\section{References}

[1] Wang, J., Paton, R., \& Page, J. R. (1999). Draping of woven fabric preforms and prepregs for production of polymer composite components. Composites Part A: Applied Science and Manufacturing, 30(6), 757-765.

[2] Skordos, A. A., Sutcliffe, M. P. F., Klintworth, J. W., \& Adolfsson, P. (2006). Multiobjective optimisation of woven composite draping using genetic algorithms. 27th International Conference SAMPE EUROPE. 